presentation. Parts one and two, the formal contributions, are mostly ponderous and repetitive to an exasperating degree and often verbose. Matters which must have been commonplace to all present, such as the difficulties caused by the rising flood of publications, the need to base decisions on sound information and the inadequacy of language for exact communication are dealt with repeatedly, at elementary level, and length. Some authors beat about a number of bushes before tackling their subjects.

Clotted jargon like "the point of discontinuance of implementation" for "the time to stop" (p.46) is mercifully rare, but tripping over verbiage is less so, e.g. "Consider the possibilities inherent in the projected construction of the Aswan High Dam Project on the Upper Nile" (p.172). As a result of all this the " 'state of the art' chapters" make 159 pages (over seventy thousand words). One art that might, in the circumstances, have been fairly fully treated, the established methods of documentation/librarianship, gets less than eleven pages.

There is a good chapter in this section on education in librarianship by Egan, Focke, Shera, and Tauber, and a glossary, especially useful for computer terms, by Mack and Taylor. The use of recorded knowledge, a difficult theme, is well, if rather tediously, covered by Egan and Henkle. They, unfortunately, repeat Bradford's dubious statement that only about one-third of useful papers in science are abstracted, without later comments on it.

Of the six chapters of part two, "Programs for the future," that by Grosch on machine computers is refreshing in style and downright in approach. Part three, "Discussion," which records very little discussion, has sixteen papers and a report of a discussion on education. The papers are short and more to the point than earlier chapters but uneven in quality. Six are on cooperative and centralized processing in various.fields; the four on language and documentation are useful introductions. Three more are on the application of operations research, information theory, and machine computing to documentation.

The eight chapters of part four report six meetings on information processing in various fields, one on machine translation and a paper on the programs of UNESCO. The single chapter of part five discusses needed research.

How is it that a book written by many distinguished people adds so little to our knowledge? It looks as if the conference tried to do too much. "Cooperative information processing" has failed in many fields; the sections on it deal largely with centralized processing, and the whole could probably have been assigned to a separate conference without loss. Education for librarianship has been discussed much and often by those competent to do so. Little good was done by fresh discussions with others. There seems to have been little control or coordination of papers read; far too much irrelevance got in. It is ironical that so many writers on this subject do not see the importance in "utilization of recorded knowledge" of the clear and concise recording of knowledge. The feeling among scholars that short, clear words and sentences are unscholarly dies hard. All this could have been overcome by thorough editing and selection, and the book cut by at least a third. As it is, the librarian and documentalist will learn little from it, and the laymen who (judging from the blurb) are expected to read it will probably lack the needed perseverance.-D. J. Campbell, Aslib, London.

\section{Solving Library Problems:}

\section{A Comment}

The article by Fernando Peñalosa and the important announcement of the establishment of the Council on Library Resources, Inc., both in the November, 1956, issue of $C R L$, called to mind a rather puzzling thing about librarians. Why is it that so many suggestions, such as that by Mr. Peñalosa, are made and so little is done about them? May I offer as an answer that we have no valid way of testing the suggestion in advance? Our only way of dealing with these and other suggested improvements is to retreat behind the statement that trying it out would cost too much money. This makes me wonder if the Council on Library Resources, Inc., will not come to merit the defi- 
nition of its parent foundation as "a large body of money completely surrounded by librarians who want some."

If our only method of dispensing finally with suggestions is to try them out-and some would be fairly costly if they should prove to be mistakes-does this not commit librarians always to a trial-and-errormethod of improvement? Does not the blind faith put in trial-and-error rather painfully indicate the lack of any general theory which would provide for a choice between experiments?

As an example, let us grant that $\mathrm{Mr}$. Peñalosa's facts and statistics are beyond reproach. Certainly a failure of communication somewhere is indicated. How shall we correct it? We could say that the failure is in the classes in the use of the library which many institutions of higher learning conduct. We could suggest an elaborate study of such courses and a very concerted effort to improve them by such grants and pilot projects as will quickly correct the condition. Or we could say, with justice, that students using the catalog should have some idea of the nature of the book they may wish to consult. Let us provide that the main entry card-which conforms to rules so complex that only librarians can reasonably be expected to know in advance how to find the main entry card for a bookshall have complete bibliographic information. The subject and title cards will have only those headings, plus the title and date of publication, to identify the book and an annotation explaining how much of the book pertains to the major subject entry, which would explain how much pertains to other subjects. There are other methods, but given only these three, how would we decide which to try?

If we choose the experiment that seems cheapest at present, we may be saddled with the one that will be most expensive to give up and the one that will be least fruitful. We need, in order to make predictions, some body of scientific theory that enables us to calculate results in advance. That is precisely what we do not have. We do have standards that avoid the issue of cost. We have a list of aspirations, but no real compilation of reasonable expectancy.
The statement of the plans for the Council on Library Resources, Inc., was painful in another way. The emphasis seems to be on importing experts to come in and assist, if not bail out, librarians. Other disciplines are to be evaluated for their usefulness in this crisis of the "glut of publication"; librarianship's methods and procedures are to be re-evaluated. While we can all be glad for help when we need it, does it not come bearing the motto "you have been tried in the balance and found wanting?" A further painful fact is the insistence on machines and devices, obviously instructed by people smart enough to deal with them. But how can we develop a machine to solve our problems until we know what the problems are?

May I respectfully suggest that the problem of research libraries is perhaps of longer range than the Council of Library Resources, Inc., seems to indicate in its statement. Indeed, librarianship is about at the point that medicine was in the period preceding Pasteur. What we must have is the basic research which will not only uncover the way of dealing with the continuing and growing demand for information, which libraries uniquely can answer, but prove theory which will enable libraries to perpetuate themselves, and improve-to the point where the increase in available material will not be considered a crisis but an opportunity for added service. What we need, I think, much more than devices, are the methods by which we can test the success or failure of our procedure by purely objective techniques, so far as scientific method has enabled good researchers to rid themselves of preconceptions and protect themselves from unseen bias.

The problem of research libraries is of sufficiently long range to make investigation of the education of librarians a prime necessity, to make the encouragement of basic research into pure theory the major endeavor of any organization in the field, and to provide for such legislative acts among librarians themselves as will replace their desire for dictation in the methods and procedures of their cooperation.-Jay E. Dailey, Paula K. Lazrus Memorial Library, National Conference of Christians and Jews, New York. 